\title{
HEPATOCYTE GROWTH FACTOR EXPRESSION IN BENIGN SALIVARY GLAND TUMORS (AN IMMUNOHISTOCHEMICAL STUDY)
}

\author{
Yasmine Alaa El-Din* and Hatem Wael Amer**
}

\begin{abstract}
Background: Cell growth factors play important roles in the biological behavior of salivary gland tumors. Hepatocyte growth factor (HGF) is a cell growth factor that is attracting a great deal of attention as a multifunctional cytokine that not only induces hepatocyte growth but also displays a wide variety of functions in various epithelial and endothelial cells.
\end{abstract}

Materials and Methods: Thirty archival paraffin-embedded specimens of cases diagnosed as normal and benign salivary gland tumors were collected (5 healthy control, 10 pleomorphic adenomas, 10 Warthin's tumors and 5 myoepitheliomas). They were prepared for routine H\& E and immunohistochemical staining with HGF.

Results: All cases revealed different HGF positive reactions with the highest optical density of HGF expression for normal salivary glands and Warthin's tumor in the benign tumors group.

Conclusion: We concluded that the presence of HGF in normal salivary tissue emphasizes the role of this factor in maintaining the physiologic functions in salivary glands. Furthermore, the most intense expression of HGF in the luminal cells of the ductal epithelium of normal salivary tissue suggested that HGF plays a role in salivary gland development.

KEYWORDS: Hepatocyte growth factor, benign salivary gland tumors, pleomorphic adenoma, Warthin's tumor, myoepithelioma, immunohistochemistry.

\section{INTRODUCTION}

Tumors of salivary glands are uncommon, but they constitute an important era in the field of oral and maxillofacial pathology. They are relatively rare neoplasms accounting for 3-10\% of all head and neck tumors, with an estimated annual incidence of 0.4-13.5 new cases per 100,000 population ${ }^{(1)}$.

The three major paired salivary glands (parotid, submandibular and sublingual), plus the hundreds of small minor salivary glands located within the

\footnotetext{
* Lecturer of oral and maxillofacial pathology, Faculty of Dentistry, October 6 University- Cairo-Egypt.

** Lecturer of oral and maxillofacial pathology, Faculty of Dentistry, Cairo University- Cairo-Egypt.
} 
submucosa of the oral cavity and oropharynx can give rise to a wide range of neoplasms. Most of the salivary gland is epithelial in origin and is of either ductal or acinar derivation ${ }^{(2)}$.

Hepatocyte growth factor (HGF) is considered a hepatotropic factor which initially identified in the serum and platelets of rats as a protein that was released by rat platelets after partial hepatomization which accelerated the liver regeneration rate ${ }^{(3,4)}$. On the other hand, the Human hepatocyte growth factor (hHGF) was initially isolated from plasma or serum of patients with fulminant hepatic failure ${ }^{(5,6)}$.

Although HGF was initially identified as a potent mitogen for hepatocytes, considerable evidence indicates that intracellular signaling pathways are driven by HGF and c-Met receptor coupling leads to multiple biological responses in a variety of cells including mitogenic, motogenic, morphogenic, neurite extension and antiapoptotic activities ${ }^{(7)}$.

Tissue types identified as sources of HGF include brain, leukocytes, pancreas, spleen, breast, liver, placenta, stomach and small intestines ${ }^{(8)}$. HGF is predominantly produced and secreted by cells of the mesenchymal /stromal compartments, however, epithelial expression of HGF in certain instances has been demonstrated ${ }^{(9 \& 10)}$.

The current study was conducted to evaluate the expression of Hepatocyte growth factor (HGF) immunohistochemically in normal and in some benign salivary gland tumors and to evaluate its role in salivary gland development.

\section{MATERIALS AND METHODS}

\section{Tissue Samples}

Thirty archival paraffin-embedded specimens of cases diagnosed as benign salivary gland tumors were collected from the Surgical Pathology Department of National Cancer Institute, Cairo University, and the Pathology Department, Faculty of Medicine, Cairo University. They were as following (5 healthy control, 10 pleomorphic adenomas, 10 Warthin's tumors and 5 myoepitheliomas). Five $\mu \mathrm{m}$ thick sections were obtained from the paraffin blocks of each of the cases and were submitted for routine $H \& E$ staining to confirm the diagnosis using the light microscopic examination.

\section{Immunohistochemical Staining}

For immunohistochemical examination, $4 \mathrm{mi}$ crometer thick sections were prepared for IHC staining. The anti-human hepatocyte growth factor (HGF) primary antibody (R\&D system, UK, cat \#AF-294-NA) antibody was reconstituted to a concentration of $15 \mathrm{mg} / \mathrm{ml}$ using ultraAb diluents (Thermo scientific, USA, cat \# TA-125-UD). Slide deparaffinization in xylol and rehydration was performed through the successful embedding of the slides in graded alcohol. Endogenous peroxidase was blocked by incubating the slides in $3 \% \mathrm{H} 2 \mathrm{O} 2$. Antigen retrieval was carried out to unmask the antigens by incubating the tissue samples in buffer citrate solution in a microwave oven at a temperature of $100 \mathrm{c}$ degrees centigrade for 15 minutes. Sections were then washed twice using buffer phosphate solution and were incubated with the primary antibody overnight at $4^{\circ} \mathrm{C}$. Biotinylated Goat AntiPolyvalent (UltraVision Detection System, Thermo scientific, USA cat \# TP-015-HD) was applied; then streptavidin conjugated to horseradish peroxidase (UltraVision Detection System, Thermo scientific USA, cat \# TP-015-HD) was applied. To visualize the antigen-antibody reaction, one drop of diaminobenzidine (DAB) chromogen was added to $2 \mathrm{ml}$ of DAB Substrate (UltraVision Detection System, Thermo Scientific, USA, cat \# TP-015-HD). Slides were immersed in Mayer's hematoxylin for counterstaining. Finally, the sections were covered by coverslips using an aqueous mounting medium.

\section{Immunostaining Analysis}

The stained sections were assessed by ordinary light microscope to detect the positive and negative immunostaining of the examined sections, as well as localization of the positive reaction within the 
tissues. All the stained sections were examined by an image analyzer computer system using the software Leica quin 500, Germany, which comprises a light microscope, a digital camera, and a microcomputer, capable of performing highspeed digital image processing. The optical density of HGF immunostaining was estimated, expressed as mean and standard deviation and used for the generation of representative graphs. ANOVA test was used for statistical analysis of the difference between groups. The student's t-test was used for pairwise comparisons. Results were less than or equal to 0.05 .

\section{RESULTS}

Immunohistochemical detection of HGF expression was done in both the control and benign groups and the results were as following:

\section{Control}

Normal salivary glands appeared with a composition of a secretory portion (serous and mucous acini) and ductal system (intercalated, striated and excretory ducts), (Fig. 1-a). Immunohistochemical examination revealed positive cytoplasmic HGF expression in the ductal cells of the control salivary tissue. However, both serous and mucous acinar cells demonstrated a negative immunoreaction (Fig. 1-b).

\section{Benign Salivary Glands Neoplasms}

\section{Pleomorphic Adenoma}

Specimens of pleomorphic adenoma demonstrated the characteristic histopathological appearance of the tumor. It showed epithelial proliferating elements in the form of masses, strands, or mono or bi-layered duct-like structures, in addition to mesenchymallike (myxoidchondroid) tissues. Two specimens demonstrated mild positive HGF immunostaining in both the epithelial element and the mesenchymallike tissues. HGF was expressed in the cytoplasm of epithelial cells arranged in duct-like structures or sheets, strands, and masses. HGF was also expressed in the myoepithelial cells within the myxoid tissue and chondroid tissues (Fig. 2a \&b).

\section{Papillary Cystadenoma Lymphomatosum (War- thin's Tumor)}

Light microscopic examination of H\&E-stained sections of Warthin's tumor revealed cystic spaces containing mucoid secretions bordered by doublelayered epithelium with occasional goblet cells. The stroma between the cystic spaces is lymphoid with numerous germinal centers (Fig. 3-a). Immunohistochemical examination revealed positive cytoplasmic HGF immunoreaction in both the basal and luminal epithelial cells lining the papillary cystic spaces, with more intense immunostaining in the luminal

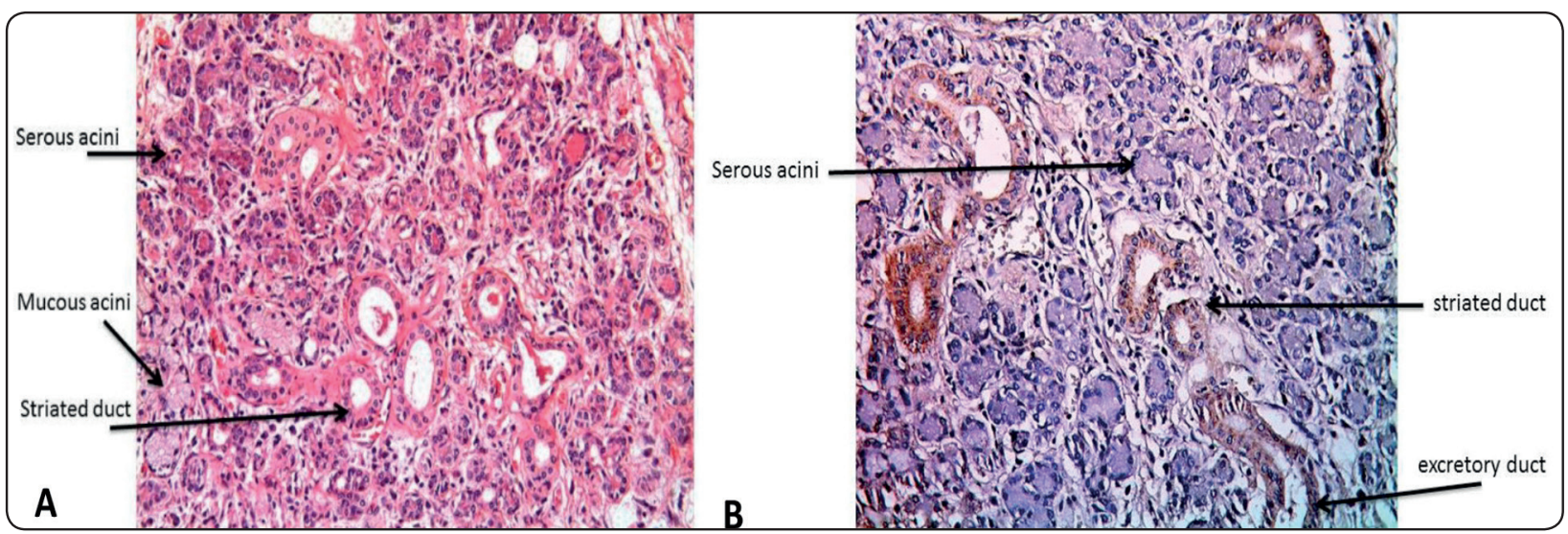

Fig. (1): Photomicrograph of normal salivary gland tissue, A) showing serous \& mucous acini and duct system (H\&E x 200). B) showing positive immunoreaction in the cytoplasm of ductal cells and absence of immunostaining in the acinar cells (antiHGF x200). 
cells. Lymphocytes and germinal centers showed negative HGF immunoexpression (Fig. 3-b).

\section{Myoepithelioma}

The cases of myoepithelioma included in this study were composed of both spindle and hyaline (plasmacytoid) cell types with a predominance of the latter type (Fig. 4-a). Weak cytoplasmic HGF immunoexpression was detected in both cell types (Fig. 4-b).

\section{Analysis of Optical Density of Hepatocyte Growth} Factor Immunoexpression Within the Studied Neoplasms:

Within the benign neoplasms, Warthin's tumor showed the greatest mean optical density (62.8 \pm 9.07), while myoepithelioma showed the lowest value $(14.7 \pm 2.21)$, (Table 1). Using the ANOVA test, the difference between the 3 studied neoplasms was highly statistically significant $(\mathrm{p}=0.000)$. The post-test pairwise comparison revealed significant differences within each pair, (Table 2).

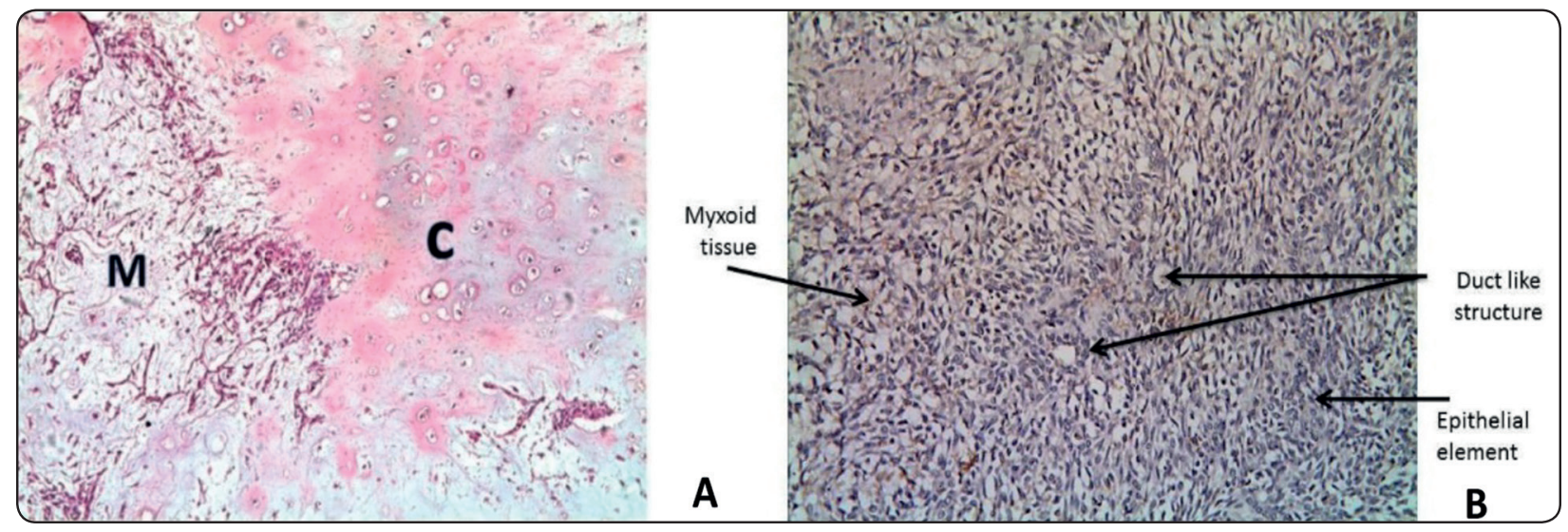

Fig. (2): Photomicrograph of pleomorphic adenoma, A) illustrating the myxoid (M) and chondroid (C) mesenchymal-like elements (H\&E x 100). B) showing mild HGF immunoreaction in both the myxoid tissue, as well as in the epithelial element (arranged in sheets or duct-like structures), (anti-HGF x 200).

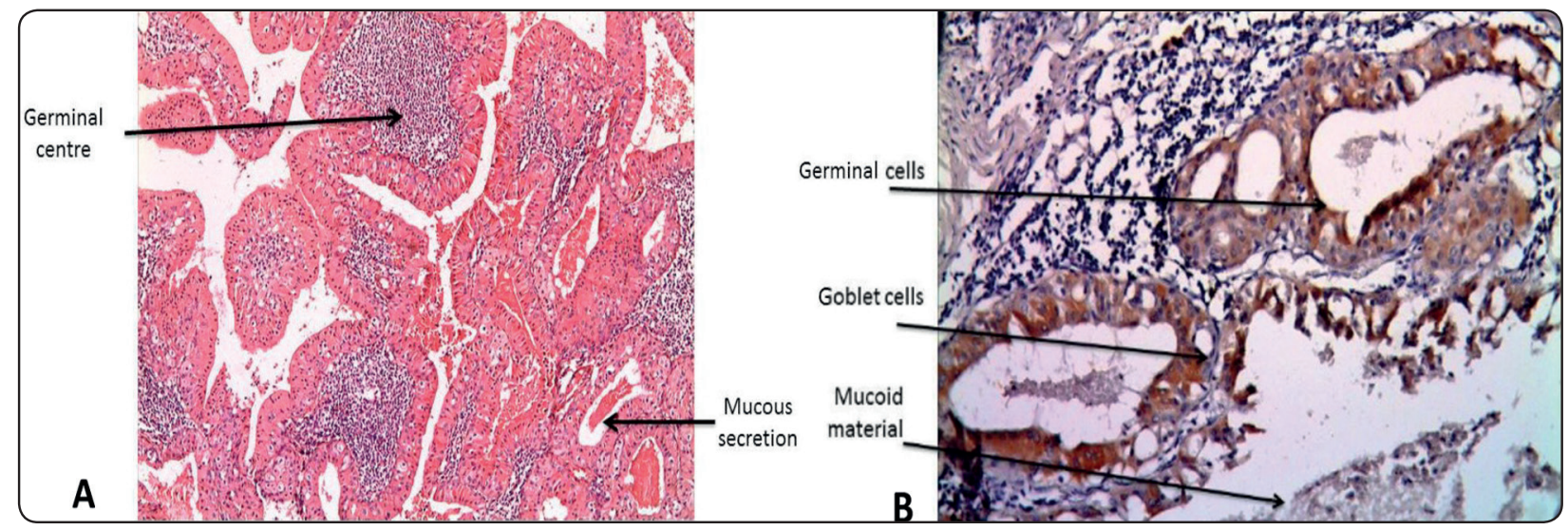

Fig. (3): Photomicrograph of Warthin's tumor, A) showing cystic spaces exhibiting papillary projections and containing mucous secretion. Germinal centers and lymphoid stroma are also demonstrated (H\&E x 100). B) showing positive HGF cytoplasmic immunoreaction in the double-layered epithelial lining of the cystic spaces (anti-HGF x 200). 


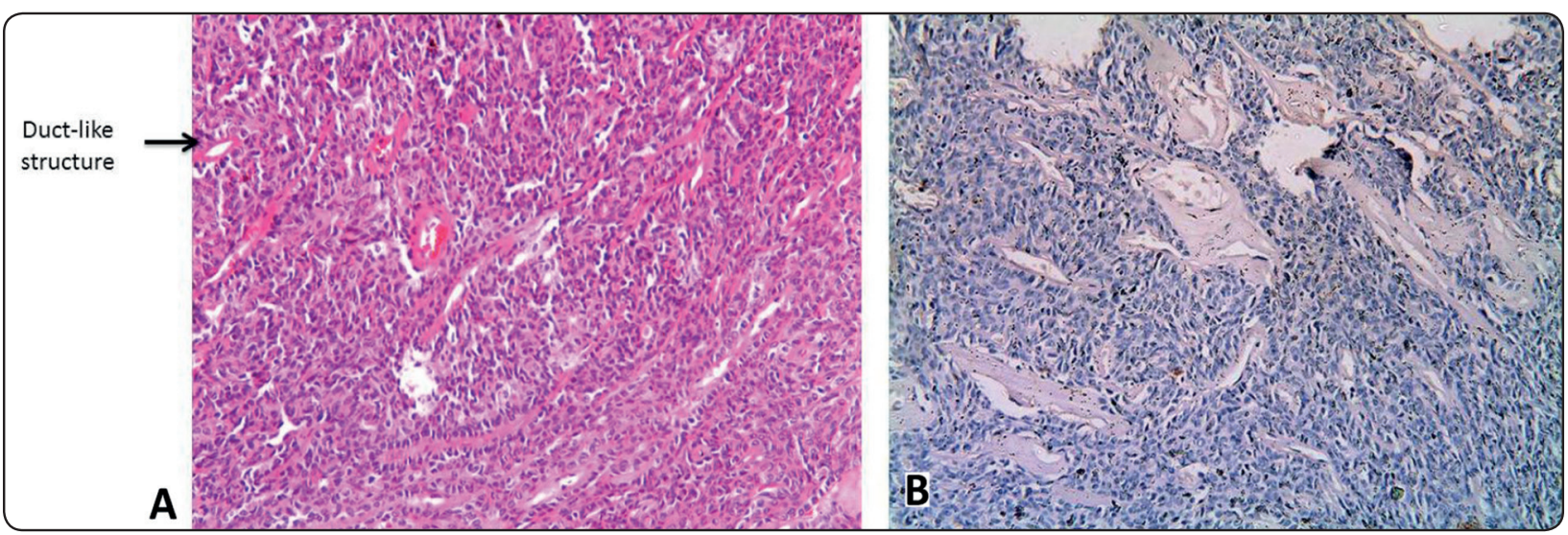

Fig (4): Photomicrograph of myoepithelioma,A) showing few spindle-shaped tumor cells, with the predominance of the plasmacytoid type (H\&E x400). B) Photomicrograph of myoepithelioma showing weak positive HGF immunoreaction (anti-HGF x200).

TABLE (1) Mean optical density of hepatocyte growth factor immunoexpression within benign salivary glands neoplasms was as following:

\begin{tabular}{ccc}
\hline Type of tumor & Mean & Standard deviation \\
\hline Warthin's tumor & 62.8 & 9.07 \\
\hline Pleomorphic adenoma & 38 & 5.72 \\
\hline Myoepithelioma & 14.7 & 2.21 \\
\hline p value (ANOVA test) & & $<\mathbf{0 . 0 0 0 1 *}$ \\
\hline
\end{tabular}

*statistically significant

TABLE (2) Statistical significance of the difference in mean optical density of HGF immunoexpression in benign salivary glands neoplasms using pair-wise comparison:

\begin{tabular}{ccc}
\hline Comparison & $\begin{array}{c}\text { Significant? } \\
(\mathbf{P}<\mathbf{0 . 0 5})\end{array}$ & t- value \\
\hline $\begin{array}{c}\text { Pleomorphic adenoma } \\
\text { versus Warthin's tumor }\end{array}$ & Yes & 6.203 \\
\hline $\begin{array}{c}\text { Pleomorphic adenoma } \\
\text { versus myoepithelioma }\end{array}$ & Yes & 5.828 \\
\hline $\begin{array}{c}\text { Warthin's tumor versus } \\
\text { myoepithelioma }\end{array}$ & Yes & 12.032 \\
\hline
\end{tabular}

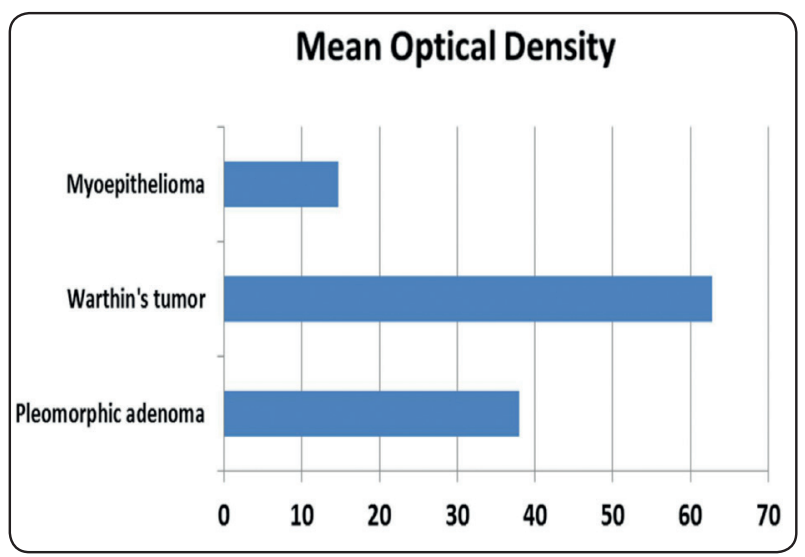

Fig. (5): Mean Optical density in different benign salivary glands neoplasms.

\section{Comparing Between the Normal Salivary Gland and Benign Salivary Gland Tumor}

Using the computer image analyzer system, the greatest optical density for HGF immunoexpression was detected in the normal salivary tissue (45.702 \pm $1.54)$, followed by benign neoplasms (38.5 \pm 24.10$)$ (Fig. 6). 


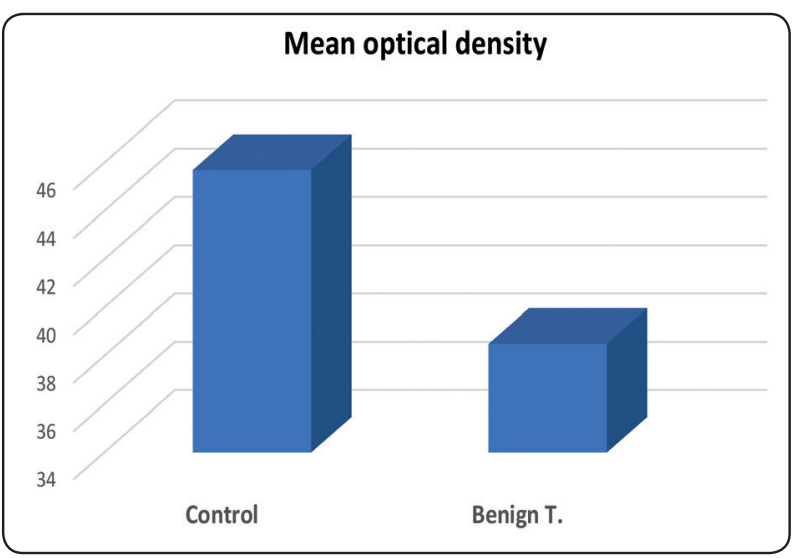

Fig. (6): Mean optical density of hepatocyte growth factor immunoexpression within normal salivary tissue and benign tumors.

\section{DISCUSSION}

Cell growth factors play important roles in the biological behavior of salivary gland tumors. Lately, Hepatocyte growth factor (HGF) is one cell growth factor that is attracting a great deal of attention as a multifunctional cytokine that not only induces hepatocyte growth but also displays a wide variety of functions in various epithelial and endothelial cells ${ }^{(1)}$.

HGF is a stromal cell-derived cytokine involved in cell proliferation and tumor growth ${ }^{(11)}$, in addition to its role in cancer invasion ${ }^{(8 \& 12)}$, angiogenesis (13) and metastasis ${ }^{(14)}$. The role of this factor in salivary gland neoplasia is not fully elucidated. In the current study, HGF expression in normal and benign salivary gland tumors was investigated using immunohistochemistry. It was found that HGF was expressed in the normal salivary gland tissues more than in the benign group. It appeared to be clearly shown in the ductal cells but was completely negative in the serous and mucous acinar cells.

The immunohistochemical findings observed in the normal salivary tissues of this study were following (Tsukinoki et al., 2003\& Tsukinoki; et al., 2005) results who found intense HGF expression in the luminal cells but observed no obvious expression in the outer ductal cells and myoepithelial cells.
Furthermore, Tsukinoki et al ${ }^{(15)}$ results also found some mild immunoreactivity of HGF in the acinar cells, however, they detected no signals in the acini when using in situ hybridization. Similarly, HGF was expressed in the cytoplasm of the ductal epithelium as reported by Aoki et al ${ }^{(17)}$, but it was not detected in acinar cells or myoepithelium of the normal salivary glands. Their findings with other growth hormones were clarified that there was a correlation between VEGF and HGF, and between EGF and HGFR, in pleomorphic adenoma which may reflect the increased expression of HGF in mixed tumors compared to other benign salivary gland tumors.

Hepatocyte growth factor (HGF) is known as a protein that causes morphogenesis and dispersion of epithelial cells. Localized expression of HGF in the luminal cells of the normal salivary glands was observed and agreed with the expression pattern which was described by Tsukinoki et al ${ }^{(15)}$ in the fetal salivary gland. These results showed that HGF expression was in epithelial strands with or without luminal structures during the early stage of salivary gland development with marked expression in luminal strands. This was proof that HGF expression is nearly associated with the development of the ductal structure during maturation in the fetal stage. Previous studies in rodent ${ }^{(18)}$ and monkey ${ }^{(19)}$ salivary glands and adult normal mammary tissues ${ }^{(20)}$ revealed the same expression profile as of this present study. In addition, Aoki et al., ${ }^{(17)}$ findings were in the same pattern of this present study which showed the HGF expression in the benign neoplasms of salivary glands was confined to the luminal cells of the tubulo-ductal structures.

In the current study, HGF's greatest optical density was detected for the normal salivary gland group. This finding agreed with Paduch et al (21) results. They clarified this by that the presence of HGF in normal salivary tissue emphasizes the role of this factor in maintaining the physiologic functions in salivary glands. 
Tsukinoki et al. ${ }^{(15)}$ results revealed intense immunoexpression of HGF in all benign salivary gland tumors, except for myoepitheliomas. These results were in agreement with our results except for a weak expression for myoepithelioma cases. HGF was highly expressed in the epithelial elements in pleomorphic adenoma, while it was moderately shown in the myxoid pattern of the tumor, whereas the least expression was for the chondroid part. In opposite to Tsukinoki et al, ${ }^{(16)}$ and Aoki et al, (17), weak immunoreactivity was observed in the myxoid and chondroid elements of pleomorphic adenoma in the current study which were against their results who reported complete absence of HGF expression in these elements. Moreover, Neville et al., 2009 added that that the highly characteristic stromal changes in pleomorphic adenoma are produced by the myoepithelial cells. This can be explained by that HGF may play an important role in the development of salivary ducts and differentiation of ductal structures of the neoplasms.

Interestingly, Karakida ${ }^{(23)}$ reported their results which were in contradiction with those noted in the current study and in the studies of Tsukinoki et al, ${ }^{(16)}$ and Aoki et al, ${ }^{(17)}$. Their results showed the highest expression of c- met (HGF receptor) in the neoplastic myoepithelium of pleomorphic adenoma.

In this study, the most intense HGF immunoexpression among all benign neoplasms was for Warthin's tumor. The reaction was shown in the luminal columnar cells lining the papillary cystic spaces, while it was completely negative in the germinal centers and lymphocytes. This expression pattern was with Tsukinoki et al ${ }^{(15)}$ who found that HGF was strongly expressed in tall columnar cells of the luminal layer, whereas there was no expression in the basal cells bordering the cystic spaces.

Recently, Błochowiak et al., (24), studied the salivary levels of different groups of salivary gland tumors. Their results revealed that there were no differences between the study groups in salivary levels of different growth factors EGF, HGF, HGFR and SRSF1. Moreover, no significant correlations were observed between any of the demographic or clinical factors and levels of these factors.

In general, the findings of the current study showed that the luminal cells of normal and benign salivary tissue expressed HGF. These findings are following other studies that pointed out that these luminal cells could produce HGF as emphasized by the observation of HGF mRNA expression.

\section{REFERENCES}

1. Andisheh Tadbir A, Khademi B, Malekzadeh M, Mardani M, Khadeni B (2013) Upregulation of serum vascular endothelial growth factor in patients with salivary gland tumor. Pathol Res Int Article ID 740582.

2. Regezi J.A, Scuibba J.J. Oral Pathology Clinical Correlations. 3rd edition. WB. Saunders Company, Philadelphia 2017; pages 135-223.

3. Nakamura T, Nawa K, and Ichihara A. Partial purification and characterization of hepatocyte growth factor from serum of hepatoectomized rats. Biochem. Biophys. Res. Commun 1984; 122:1450-1459.

4. Nakamura T, Nishizawa T, Hagiya M, Seki T, Shimonishi M, Sugimura A, et al. Molecular cloning and expression of human hepatocyte growth factor. Nature. 1989; 342(6248):440-443.

5. Gohda E, Tsubouchi H, Nakayama H, Hirono S, Sakiyama O, Takahashi K, Miyazaki H, Hashimoto S, Daikuhara Y: Purification, and partial characterization of hepatocyte growth factor from plasma of a patient with fulminant hepatic failure. J Clin Invest 1988; 81:414-9.

6. Arakaki N, Kawakami S, Nakamura O, Ohnishi T, Miyazaki H, Ishii T, Tsubouchi H, Daikuhara Y. Evidence for the presence of an inactive precursor of human hepatocyte growth factor in plasma and sera of patients with liver diseases. Hepatol. 1995; 22(6):1728-34.

7. Funakoshi H, Nakamura T. Hepatocyte growth factor: from diagnosis to clinical applications. Clin Chim Acta. 2003; 327(1-2):1-23.

8. To $\mathrm{C} \mathrm{T}$, and Tsao M S. The roles of hepatocyte growth factor / scatter factor and Met receptor in human cancers. Oncol. Rep. 1998; 5:1013-1024.

9. Tuck AB, Park M, Sterns EE, Boag A, Elliott B. Co-expression of hepatocyte growth factor and receptor (Met) in human breast carcinoma. Am J Pathol 1996; 148: 225-32. 
10. Zang YW, vande Woude GF. HGF/SF-met signaling in the control of branching morphogenesis and invasion. J Cell Bio-chem 2003; 88: 408-17.

11. Ho RT, Liew CT, Lai KN. The expression of hepatocyte growth factor (HGF) and interleukin 6 (IL6) in damaged human liver and kidney tissues. Hepatogastroentrology 1999; 46:1904-9.

12. Uchida D, Kawamata H, Omotehara F, Nakashiro Ki, Kimura-Yanagawa T, et al: Role of $\mathrm{HGF} / \mathrm{c}-$ met system in invasion and metastasis of oral squamous cell carcinoma cells in vitro and its clinical significance. Int $\mathrm{J}$ Cancer 2001; 93: 489- 496.

13. Belle EV, Witzenbichler B, Chen D, Silver M, Chang L, Schwall R, Isner JM: Potentiated angiogenic effect of scatter factor/hepatocyte growth factor via induction of vascular endothelial growth factor: the case for paracrine amplification of angiogenesis. Circulation 1998; 97:381-390.

14. Xia S \& Laterra J. Hepatocyte growth factor increases mitochondrial mass in glioblastoma cells. Biochem Biophys Res Commun 2006; 345:1358-64.

15. Tsukinoki K, Yasuda M, Asano S, Karakida K, Ota Y, Osamura R Y, and Watanabe Y. Association of hepatocyte growth factor expression with salivary gland tumor differentiation. Pathol. Int. 2003; 53: 815-822.

16. Tsukinoki K, Yasuda M, Miyoshi Y, Mori Y, Otsuru M, Saruta J, et al: Role of hepatocyte growth factor and c-Met Receptor in neoplastic conditions of salivary glands. Acta Histochem. Cytochem 2005; 38: (1)25-30.

17. Aoki T, Tsukinoki K, Kurabayashi H, Sasaki M, Yasuda M, Ota Y, Watanabe Y, Kaneko A, Hepatocyte growth factor expression correlates with cyclooxygenase- 2 pathway in human salivary gland. Oral Oncol. 2006; 42:51-56.

18. Amano O, Matsumoto K, Nakamura T, lseki S. Expression and localization of hepatocyte growth factor in rat submandibular gland. Growth Factors. 1994; 10: 145-151.

19. Moroto T\& Kamada A: Expression and localization of HGF mRNA in monkey submandibular gland. J Osaka Dent University 1998; 32:37-42.

20. Wang Y, Selden AC, Morgan N, Stamp GW H, Hodogson HJF. Hepatocyte growth factor/Scatter factor expression in human mammary epithelium. Am J Pathol 1994; 144: $675-82$

21. Paduch R, Jakubowicz-Gil J, Niedziela P. Hepatocyte growth factor (HGF), heat shock proteins (HSPs) and multidrug resistance protein (MRP) expression in coculture of colon tumor spheroids with normal cells after incubation with interleukin-1beta (IL-1beta) and/or camptothecin (CPT-11). Indian J Exp Biol. 2010; 48(4):354-64.

22. Neville B, Damm D, Allen C, Bouquot J. Oral and Maxillofacial Pathology, $3^{\text {rd }}$ edition, Saunders, USA 2009;406-410.

23. Karakida K. HGF, c-Met and Bcl-2 expression and its role in histogenesis of benign salivary gland tumors. J. Jpn. Stomatol. Soc. 2001; 50: 169-181.

24. Błochowiak, K; Sokalski J; \& Golusińska,E \& Trzybulska, D; Witmanowski, H; Bodnar, M\& Marszałek, A: Salivary levels and immunohistochemical expression of selected angiogenic factors in benign and malignant parotid gland tumors. Clinical Oral Investigations (2019) 23:995-1006. 